\title{
Commentary \\ The Search for Geometrical Parameters That Represent the Dynamic Nature of Phyllotaxis in Plants
}

\author{
Denis Barabé ${ }^{1}$ and Christian Lacroix ${ }^{2, *}$ \\ 1 Institut de Recherche en Biologie Végétale, Université de Montréal, 4101 Sherbrooke Est, \\ Montreal, QC H1X 2B2, Canada; barabedenis1@gmail.com \\ 2 Department of Biology, University of Prince Edward Island, 550 University Avenue, \\ Charlottetown, PE C1A 4P3, Canada \\ * Correspondence: lacroix@upei.ca
}

check for updates

Citation: Barabé, D.; Lacroix, C. The Search for Geometrical Parameters

That Represent the Dynamic Nature of Phyllotaxis in Plants. Symmetry 2022, 14, 184. https://doi.org/ $10.3390 /$ sym 14020184

Academic Editor: Margarita

V. Remizowa

Received: 20 November 2021

Accepted: 14 January 2022

Published: 18 January 2022

Publisher's Note: MDPI stays neutral with regard to jurisdictional claims in published maps and institutional affiliations.

Copyright: (c) 2022 by the authors. Licensee MDPI, Basel, Switzerland. This article is an open access article distributed under the terms and conditions of the Creative Commons Attribution (CC BY) license (https:// creativecommons.org/licenses/by/ $4.0 /)$.

\begin{abstract}
The shoot apical meristem (SAM) is the main growth centre that produces lateral organs such as leaves in specific and precise symmetrical patterns. The main goal of this commentary is to explore the link between phyllotactic parameters such as the plastochrone ratio $(R)$ as well as $\Gamma$ (relationship between the size of the SAM and the size of primordia) and growth processes involved in the expression of symmetrical patterns at the level of the SAM. It is also possible to deduce the values of these parameters from measures of the apical area and the radius of the SAM. A comparative analysis of phyllotactic parameters for three species (Begonia scabrida, Euterpe oleracea, and Anagallis arvensis) for which 'dynamic' data are available reveals that empirical and theoretical values of $R$ and $\Gamma$ can differ, indicating that characters defining these parameters are subject to developmental constraints that in turn determine the boundary conditions for the dynamic manifestation of phyllotactic patterns. One of the main challenges that remains is the ability to consistently and effectively observe the dynamic changes taking place at the SAM (in real time) over an extended period.
\end{abstract}

Keywords: plastochrone ratio; parameter $\Gamma$; Begonia scabrida; Euterpe oleracea; Anagallis arvensis; relative mean apical area; morphogenesis in $4 \mathrm{D}$

\section{Introduction}

In plant biology, one of the most astonishing manifestation of principles of symmetry is certainly phyllotaxis. Phyllotaxis corresponds to the patterns made by similar elements (e.g., leaves, scales, and floral parts) on shoot systems [1,2]. On plants stems or meristems, three main types of phyllotactic patterns can be recognized: spiral (leaves inserted in a spiral around the stem), whorled (two or more leaves inserted at the same node), and distichous (leaves inserted alternatively in two rows on opposite side of the stem). When there is a twisting of the two leaf rows in a distichous system, we have a spirodistichous system. Atypical patterns that occur naturally [3] or are artificially generated in mutants [4] also exist where leaves are distributed more or less randomly around the stem [5]. At the level of the shoot apical meristem (SAM), where the repeated initiation of primordia and their establishment takes place, corresponding fluctuations in the size of the shoot apex is common across many phyllotactic patterns, e.g., [6,7].

A variety of geometrically different parameters (e.g., mathematical, chemical, and physical) have been used throughout the historical development of the field of phyllotaxis. However, four parameters are generally and consistently used in experimental and theoretical studies: angle of divergence, number of opposed parastichies, plastochrone ratio, and parameter $\Gamma$. The angle of divergence $d$ is an angular value between two successive leaves $(n, n+1)$ and the center of the SAM (Figure 1). Opposed parastichies are hypothetical oblique or secondary spiral lines joining leaves; these lines run in opposite directions, intersect at an angle close to 90 degrees at the site of each leaf, and are represented by 
the designation $(m, n)$ where $m$ and $n$ represent the number of spirals in each direction (Figure 2).

The plastochrone ratio $=\frac{r_{n+1}}{r_{n}}$, represents the relationship between the distance of two successive leaves from the center of the SAM (Figure 1). The rise (s) which is used in a cylindrical representation corresponds to the plastochrone ratio $(R)$ in a planar representation. The rise is defined as the vertical distance between two consecutive leaves on a cylindrical lattice. As outlined in Jean [8], the two parameters are related by the formula $s=\ln \left(\frac{R}{2 \pi}\right)$. The parameter $\Gamma$ corresponds to a relationship between the size of the SAM and the size of primordia. Van Iterson [9] (p. 83) used parameter $b$ to analyse the geometrical arrangement of leaves at the level of the SAM. Parameter $b=\frac{\delta}{2 \pi L}=\frac{l}{\pi L}$, where $(\delta)$ is the diameter of the primordium and $(2 \pi L)$ is the perimeter of the SAM; $l$ corresponds to the radius of the primordium. Instead of the circumference, one can simply use the radius of the apex as it is the case for parameter $\Gamma$ defined by Douady and Couder [10], where $\Gamma=\frac{\delta}{L} ; \delta$ corresponds to the width of the primordium and $L$ to the radius of the SAM (Figure 1).

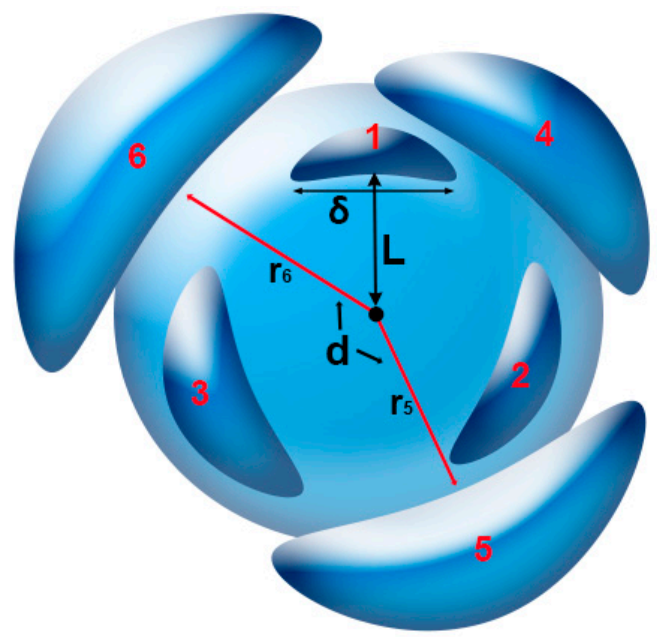

Figure 1. Spiral pattern of phyllotaxis highlighting specific parameters. Leaf number refers to the sequence of initiation of successive primordia from youngest to oldest. $d$, divergence angle, highlighted on the figure as the angle between leaf primordia 5 and 6 ; plastochrone ratio $(R)$, ratio of $\mathrm{r}_{6}$ over $\mathrm{r}_{5}$ representing the distances from primordia 5 and 6 to the center of the SAM (black dot); parameter $\Gamma$, the width of a primordium $(\delta)$ as indicated on primordium 1 divided by the radius of the SAM (L) represented by the distance of primordium 1 to the center of the SAM. (Modified from [5]).

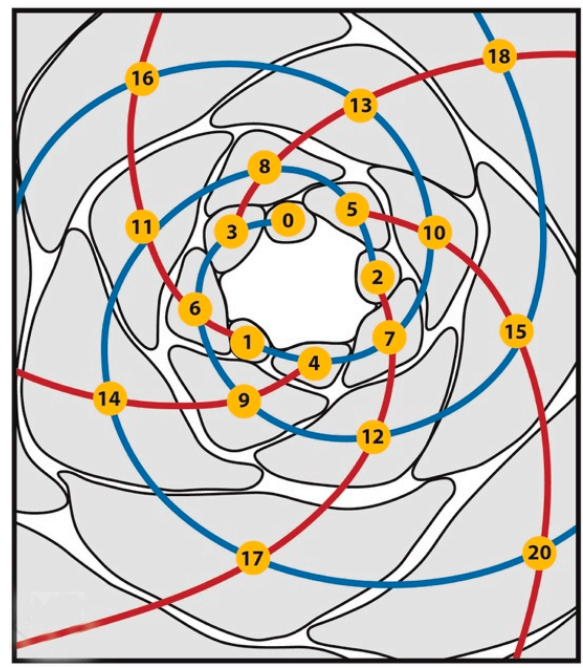

Figure 2. Transverse section of the shoot tip of Sempervicum calacaratum showing a phyllotactic system with a $(5,3)$ contact parastichy pair represented by red and blue lines, respectively (Adapted from [11]). 


\section{The Relationship between Phyllotactic Parameters}

The parameters listed above allow for the analysis of data and comparisons between models in a rigorous theoretical framework. In representations of phyllotactic trees (bifurcation diagrams linking the number of parastichies to the angle of divergence), parameters $\mathrm{r}, R$, and $\Gamma$ constitute the bifurcation parameters from one phyllotactic system to another. In these diagrams there is a correlation between the values of these parameters. For example, in spiral continuous systems, when the values of $\mathrm{r}, R$, and $\Gamma$ decrease, the value of the angle of divergence decreases $\left(180^{\circ} \rightarrow 137^{\circ}\right)$, and the number of opposed parastichies increases $((3,5) \rightarrow(5,8))$.

Determining the values of some phyllotactic parameters in real time remains one of the main challenges in phyllotaxis. For example, the plastochrone ratio is an indirect representation [12] of the plastochrone, which corresponds to the time interval between the appearance of two successive leaves. It is assumed that a longer distance (high value of $R$ ) between two primordia will correspond to a longer plastochrone. The real time tracking of the initiation of primordia in two different phyllotactic patterns was observed by using experimental data from Begonia scabrida [13,14], which is characterised by a distichous system, and Anagallis arvensis [15], which is characterized by a spiral system. Based on these studies, the plastochrone of $B$. scabrida ( 15 days $<\mathrm{T}<20$ days) is greater than that of $A$. arvensis ( 1.7 days $<\mathrm{T}<1.9$ days). The higher values in spirodistichous systems are in agreement with the higher value of parameter $\Gamma$ and the plastochrone ratio $(R)$ predicted by theoretical systems. By using empirical data collected from a variety of species, Rutishauser [16] found a correlation between the leaf arc (the angle between the edges of a primordium in relation to the center of the SAM), the angle of divergence, and the plastochrone ratio. In distichous $\left(180^{\circ}\right)$ and spirodistichous $\left(145-179^{\circ}\right)$ systems, the leaf arc ranges within $270-360^{\circ}$ and the plastochrone ratio within 1.25-2.3. In Fibonacci spiral systems $\left(120-144^{\circ}\right)$ the leaf arc varies within $4.5-360^{\circ}$ and the plastochrone ratio within 1.0-1.67. In other spiral systems $\left(56-151^{\circ}\right)$ the leaf arc varies within $35-75^{\circ}$ and the plastochrone ratio within 1.012-1.046. There is a positive empirical correlation between the plastochrone ratio and the leaf arc. In plants with a leaf arc $i \leq 270^{\circ}$ (distichous and spirodistichous systems), the value of the plastochrone ratio is $R \geq 1.25$. However, some spiral systems have a leaf arc that is greater than $270^{\circ}$, particularly in monocotyledones. For example, in palms such as Euterpe oleracea, characterized by a spiral system with an average divergence angle of $137^{\circ}$, the leaf arc is $360^{\circ}$ [17].

Using the relationship between the size of the apex and that of a primordium as a starting point, Richards [12] developed the notion of area ratio (A), or relative mean apical area, which was analyzed many years later by Jean [8]. In a planar representation, the area ratio is defined by

$$
A=\frac{\text { mean apical area }}{\text { primordium area upon initiation }} .
$$

During a plastochrone, the apex expands exponentially from a minimal area $(c)$ to a maximal area $(C)$. Therefore, the mean apical area is $(C-c) /(\ln C-\ln c)$, and the primordium area is $(C-c)$. From this we can deduce that the area ratio $A=1 / \ln (C / c)$. Interestingly, the area ratio is linked to the plastochtone ratio [8] by the equation

$$
A=1 /(2 \ln R)
$$

It follows that when we know $A$, it is possible to obtain a theoretical value for $R$. There is also a relationship between $A, \mathrm{~b}$, and $\Gamma$. We know that

$$
A=\frac{1}{\ln \left(\frac{C}{c}\right)}
$$


then

$$
A=\frac{1}{\ln \left(\frac{\pi a^{2}}{\pi L^{2}}\right)}
$$

where $a$ is the radius of maximal area $(C)$ and $L$ the radius of the minimal area $(c)$. Previously we defined the parameter $\Gamma=\frac{\delta}{L}$. By putting the value of $L$ in Equation (1), we obtain

$$
A=\frac{1}{\ln \frac{a^{2}}{\left(\frac{\delta}{\Gamma}\right)^{2}}}
$$

From this equation it is possible to isolate $\Gamma$. We obtain

$$
\ln \Gamma=\frac{1}{2 A}+\ln \left(\frac{\delta}{a}\right)
$$

and finally

$$
\Gamma=e^{\frac{1}{2 A}+\ln \left(\frac{\delta}{a}\right)}
$$

Therefore, it is possible to calculate a theoretical value for $R$ and $\Gamma$ by using the empirical values of $A$ and $a$.

From the empirical value of $R$, Rutishauser [16] calculated a theoretical value for the maximal apical area $(C)$ and the minimal apical area $(c)$ by using Formula 1 above. On the SAM of Picea abies, with a spiral phyllotactic system $(8,13)$ and a relatively low value of $R$ (1.06), the size of $C$ is nearly equal to $c$, given that the apical meristem is much bigger than the youngest leaf primordia. However, in Caltha palustris, characterized by a spirodistichous system and $R=1.74$, the shoot apex loses about $2 / 3$ of its area $(C)$ during the initiation of a new leaf. This is a general characteristic of distichous and spirodistichous systems, and it was observed on diagrams of the SAM published a long time ago by Haccius [18]. However, we can also observe a very high value of $A$ in certain spiral systems, such as that of E. oleracea (Table 1) and many monocotyledons [19].

Table 1. Calculations of phyllotactic parameters based on previous studies of Begonia scabrida, Euterpe oleracea, and Anagallis arvensis. A, relative mean apical area; $\mathrm{d}$, divergence angle; $\mathrm{P}$, plastochrone in days; $\Gamma_{\mathrm{e}}$, empirical value of parameter $\Gamma ; \Gamma_{\mathrm{t}}$, theoretical value of $\Gamma ; \mathrm{R}_{\mathrm{e}}$, empirical value of the plastochrone ratio; $\mathrm{R}_{\mathrm{t}}$, theoretical value of the plastochrone ratio; ${ }^{1}$ From [13]; ${ }^{2}$ Calculated from Figure $2 \mathrm{C}$ in [13]; ${ }^{3}$ Calculated from equation $1 ;{ }^{4}$ Measured on Figure $2 \mathrm{C}$ in [13]; ${ }^{5}$ Calculated from equation $2 ;{ }^{6}$ From [17]; ${ }^{7}$ Estimated from the value obtained by [20] on the oil palm Elaeis guineensis; ${ }^{8}$ Measured on Figure 1 in [17]; ${ }^{9}$ Measured on Figures 1 and 5 in [21].

\begin{tabular}{cccccccc}
\hline Species & $\mathbf{d}$ & $\mathbf{P}$ (Days) & $\mathbf{A}$ & $\mathbf{R}_{\mathbf{e}}$ & $\mathbf{R}_{\mathbf{t}}$ & $\boldsymbol{\Gamma}_{\mathbf{e}}$ & $\boldsymbol{\Gamma}_{\mathbf{t}}$ \\
\hline Begonia scabrida & $165-180^{\circ} 1$ & $15-20^{1}$ & $0.59^{2}$ & $1.3^{1}$ & $2.3^{3}$ & $4^{4}$ & $7.7^{5}$ \\
Euterpe oleracea & $127-135^{\circ} 6$ & $\approx 17^{7}$ & $0.92^{2}$ & $1.5^{6}$ & $1.7^{3}$ & $3.5^{8}$ & $5.5^{5}$ \\
Anagallis arvensis & $137.5^{\circ}$ & $1.7-1.9^{9}$ & $15.3^{9}$ & $1.3^{9}$ & $1.4^{9}$ & $0.6^{9}$ & $0.9^{5}$ \\
\hline
\end{tabular}

\section{A Comparison of Three Species}

For the analysis of certain parameters, we selected three species with a very different SAM morphology and for which it was possible to determine the plastochrone in real time: Begonia scabrida, Euterpe oleracea, and Anagallis arvensis (Table 1). Since the plastochrone is closely associated with the growth mode of the apex, it is interesting to calculate a theoretical value of $R$ from the empirical value of $A$, a parameter that directly represents the dynamic nature of the apex (Table 1). Rutishauser [16] did not observe a plastochrone ratio value higher than 2.3 in his large sample of species, although certain theoretical models [8] predict a value up to 10 . This may indicate that the growth mode of the plant imposes a limit on the maximum empirical value of the plastochrone. In our comparative analysis (Table 1), the values of the theoretical plastochrone ratio $\left(R_{t}\right)$ as well as the ratio between the size of 
the primordium and size of the SAM $\left(\Gamma_{t}\right)$ are higher than the empirical values $\left(R_{e}\right.$ and $\left.\Gamma_{e}\right)$. This indicates that the empirical values of $R$ and $\Gamma$ do not support the assumption of the exponential growth of the SAM.

Even though different values of $\Gamma$ correspond to different phyllotactic systems in theoretical models, it is not always the case in planta. How can we explain the high values of $\Gamma$ in a typical spiral pattern (E. oleracea) or spirodistichous pattern (B. scabrida)? Parameter $\Gamma$ is a manifestation of the mode of development and the overall morphology of the apex. According to Douady and Couder [10], the genetic system does not directly determine the phyllotaxy; rather, it lays the morphological foundations on which the iteration process will take place. The characters that are used to measure parameter $\Gamma$ are determined genetically and constitute a developmental constraint on the plant and consequently the phyllotactic pattern that will emerge. In other words, the ratio of the primordium size to the SAM size is controlled by the genetic system that in turn determines the boundary conditions of the dynamic system [5].

In biophysical systems, there is also a parameter that plays an analogous role to parameter $\Gamma$. It is the ratio between the radius of the generative zone (Z) (R in [22]) and the intrinsic wavelength $(\Lambda)$ generating the primordium [22]: $\Gamma^{*}=\frac{Z}{\Lambda}$. This is roughly the inverse of Douady and Couder's parameter. When the size of the primordium decreases, $\Gamma^{*}$ and the number of parastichies increase contrary to what occurs with $\Gamma$. However, the model of Shipman and Newell is based on the premise that the ratio of the width and circumference of the generative region to the intrinsic wavelength linked to the buckling of the tunica (representing the appearance of a primordium) is large. In a distichous system, where $\Gamma=2$, the value of the radius of the generative zone should be two times greater than the intrinsic wavelength. It is difficult to imagine how this can occur on a SAM such as that of $B$. scabrida where the generative zone is smaller than the primordium. Similarly, in $E$. oleracea, to generate a $(3,5)$ parastichy pair, the ratio between the radius of the SAM and that of the primordium would need to be equal to 5 . This is surely not the case, because nearly the entire surface of the SAM is involved in the formation of individual primordia.

\section{General Discussion and Conclusions}

There is a tremendous amount of variation in terms of the relative size between leaf primordia and the SAM on which they develop. Early stages of development of leaf primordia include a spectrum of forms, some of which consist of clearly delineated bulges on the periphery of a distinguishable and larger SAM, and others where the primordium is large enough to take up a sizable portion of the SAM [23]. The initiation and development of monocotyledonous leaves typically differs significantly from those of eudicots. The sheathing leaf base characteristic of monocots is a feature that is also visible during early stages of initiation. The emerging primordium extends laterally to the extent that it can completely encircle the periphery of the SAM, resulting in a unique packing (encasement) of successive leaves. These early differences in development create unique patterns that can be used to further test the relationships between phyllotactic parameters such as $R$ and $\Gamma$.

The value of the parameter $\Gamma$ remains constant along a stem in contrast to the angle of divergence and the plastochrone ratio [17]. In different theoretical models, a parameter equivalent to $\Gamma$ can be used, linking the size of the primordium to the size of the SAM directly or indirectly. In chemical models, it is the ratio of the diameter of the SAM to the diameter of the inhibition field. In biochemical models, it is the size of the central zone, and in biomechanical models it is the ratio between the radius of the SAM and the intrinsic wavelength. In the model of Smith et al. [24], if the threshold value of the inhibiting effect of primordia remains constant, one can observe a transition from distichous to spiral patterns by changing the size of the apex. In the biochemical model of Smith et al. [25], a change from a distichous to decussate phyllotactic pattern involved increasing the indoleacetic acid (IAA) concentration as well as decreasing the width of the peripheral zone and increasing the size of the central zone on the SAM. Let us note that it has been shown empirically that changes in the size of the apex are correlated with variations in phyllotactic patterns [26,27]. 
The development of plant axes is marked by two phases: the development of primordia on the surface of the SAM and the emergence of a phyllotactic pattern [5]. Different explanations (e.g., biochemical or physical) can lead to the manifestation of the same phyllotactic pattern. However, the emergence of a phyllotactic pattern is intimately tied to the establishment of periodicity in the form of an iterative process. As noted previously by Barabé and Lacroix [5] (p. 201): "The convergence between models may be the consequence of the iteration rules involved in the propagation of the phyllotactic patterns during plant growth or more generally over time". Therefore, similar patterns in different species may be subject to the same rules governing the reiteration processes and are not necessarily linked to chemical or biological causation.

Previously, we used the notion of open systems and closed systems to characterize two types of phyllotactic structures in plants $[5,28]$. In open systems, such as the stem of Arabidopsis thaliana and Anagallis arvensis, one (or more) lateral element is produced periodically around the SAM by an iterative process, and the central zone remains devoid of primordia during the period of growth. On the other hand, in closed systems, characterized by flowers and compact inflorescences such as the spadix of Araceae and the capitulum of Asteraceae, the floral primordia will progressively cover nearly all the meristematic surface. Let us note that the notion of a closed phyllotactic system refers to the mode of development of the structure as a whole and not the presence (or not) of a terminal flower. For example, in this framework the inflorescence of Gerbera hybrida constitutes a closed system, although morphologically speaking it is not a closed inflorescence sensu stricto [29]. In this commentary we discussed parameters linked to open systems, for example B. scabrida and A. arvensis. It has always been assumed that these parameters can also be used to describe closed systems. The recent work of Zhang et al. [30] takes a fresh look at this issue. The authors consider that the emergence of Fibonnacci sequences in G. hybrida heads cannot be explained by models that focus on the divergence angle and sequential addition of new primordia along a genetic spiral. The exact order in which primordia emerge is not observable and, according to the authors, would not explain the resulting pattern. The phyllotactic pattern results from local interactions between individual primordia without a linear temporal ordering on the entire capitula. Godin et al. [31] also showed theoretically that local interactions can progressively canalyze the arrangement of elements toward spiral patterns. Zhang et al. [30] concluded that many parameters used in the description of phyllotaxis, such as plastochrone, divergence angle, and generative spiral, are not relevant for the explanation of phyllotactic patterns in the capitula of G. hybrida. This suggests that the explanation of the emergence of phylllotactic patterns in open systems and closed systems may not always be the same. Therefore, a comparative empirical and theoretical analysis of the emergence of phyllotactic patterns in open systems and closed systems would be worthwhile to gain a better understanding of phyllotaxis. Additionally, the high value of $\Gamma$ in both spirodistichous and spiral systems indicates that different morphologies can lead to similar spiral patterns. We cannot explain the presupposed prevalence of Fibonacci phyllotaxis in plants solely by the uniformity of the organogenesis processes.

Advances in image analysis software such as MorphoGraphX [32,33] and microscopy, more specifically laser confocal scanning microscopy imaging capabilities and variable pressure vacuum in scanning electron microscopy (SEM) to view living specimens, have contributed to the elucidation of the growth dynamics of the SAM in $4 \mathrm{D}$ (i.e., the observation of a three-dimensional structure over time) [34]. The protocol developed by Dumais and Kwiatkowska [21], which adapted the replica method of Green [35] and a stereoscopic reconstruction of the apex, has been very useful to study the values of parameters $R$ and $\Gamma$ in real time on the SAM. However, the main challenge that remains is the ability to live image a SAM over an extended period. To achieve this, a view of the exposed surface of the SAM is required, but it is often obstructed by older leaves that shield younger primordia. Consequently, several primordia need to be removed while keeping the plant specimen alive for repeated observations. Additionally, the size of the living tissue can pose additional limitations when it comes to viewing the structures of interest under a 
microscope, because it is not feasible under most circumstances to keep the SAM connected to the rest of the whole plant. The development of micro-tissue culture platforms to keep tissues alive for an extended period and/or further enhancements in light-sheet and super-resolution microscopy [36] may prove useful on this front.

Author Contributions: D.B. and C.L. participated equally in the conceptualization, writing, review, and editing of this manuscript. All authors have read and agreed to the published version of the manuscript.

Funding: This research was funded by the Natural Sciences and Engineering Research Council of Canada (NSERC) in the form of a Discovery Grant to C.L.

Acknowledgments: The authors thank the editors and reviewers for helpful comments during the review process.

Conflicts of Interest: The authors declare no conflict of interest. The funding agency had no role in the design of the study; in the collection, analyses, or interpretation of data; in the writing of the manuscript; or in the decision to publish the results.

\section{References}

1. Yonekura, T.; Sugiyama, M. Symmetry and its transition in phyllotaxis. J. Plant Res. 2021, 134, 417-430. [CrossRef] [PubMed]

2. Yin, X. Phyllotaxis: From classical knowledge to molecular genetics. J. Plant Res. 2021, 134, 373-401. [CrossRef] [PubMed]

3. Rutishauser, R. Acacia (wattle) and Cananga (ylang-ylang): From spiral to whorled and irregular (chaotic) phyllotactic patterns-A pictorial report. Acta Soc. Bot. Pol. 2016, 85, 3531. [CrossRef]

4. Itoh, J.I.; Kitano, H.; Matsuoka, M.; Nagato, Y. SHOOT ORGANIZATION genes regulate shoot apical meristem organization and the pattern of leaf primordium initiation in rice. Plant Cell 2000, 12, 2161-2174. [CrossRef]

5. Barabé, D.; Lacroix, C. Phyllotactic Patterns: A Multidisciplinary Approach; World Scientific: Singapore, 2020; 273p.

6. Lacroix, C.; Barabé, D.; Jeune, B. Early stages of initiation of two types of leaves in Thuja occidentalis (easter white cedar). Can. J. Bot. 2004, 82, 598-606. [CrossRef]

7. Yin, X.; Lacroix, C.; Barabé, D. Phyllotactic transitions in seedlings: The case of Thuja occidentalis. Botany 2011, 89, 387-396. [CrossRef]

8. Jean, R.V. Phyllotaxis: A Systemic Study in Plant Morphogenesis; Cambridge University Press: Cambridge, UK; New York, NY, USA, 1994; 386p.

9. Van Iterson, G. Mathematische und Mikroskopisch-Anatomische Studien über Blattstellungen nebst Betraschtungen über den Schelenbau der Miliolinen; Gustav Fischer: Jena, Germany, 1907.

10. Douady, S.; Couder, Y. The phyllotactic pattern as resulting from self-organization in an iterative process. In Symmetry in Plants; Jean, R.V., Barabé, D., Eds.; World Scientific: Singapore, 1998; pp. 539-570.

11. Church, A.H. On the Interpretation of Phenomena of Phyllotaxis; Facsimile of the Original Edition; Hafner Publishing Co.: New York, NY, USA, 1920; 1968p.

12. Richards, F.J. Phyllotaxis: Its quantitative expression and relation to growth in the apex. Phil. Trans. R. Soc. Lond. 1951, 235B, 509-564.

13. Barabé, D.; Lacroix, C.; Jeune, B. Following the initiation and development of individual leaf primordia at the level of the shoot apical meristem (SAM): The case of distichous phyllotaxis in Begonia. Ann. Bot. 2007, 99, 555-560. [CrossRef]

14. Barabé, D.; Jeune, B.; Lacroix, C. Comparison between theoretical and empirical parameters in phyllotaxis: The case of Begonia. Riv. Biol. 2009, 102, 157-164. [PubMed]

15. Kwiatkowska, D.; Dumais, J. Growth and morphogenesis at the vegetative shoot apex of Anagallis arvensis L. J. Exp. Bot. 2003, 54, 1585-1595. [CrossRef]

16. Rutishauser, R. Plastochrone ratio and leaf arc as parameters of a quantitative phyllotaxis analysis in vascular plants. In Symmetry in Plants; Jean, R.V., Barabé, D., Eds.; World Scientific: Singapore, 1998; pp. 171-212.

17. Barabé, D.; Bourque, L.; Yin, X.; Lacroix, C. Phyllotaxis of the palm Euterpe oleracea Mart. at the level of the shoot apical meristem. Botany 2010, 88, 528-536. [CrossRef]

18. Haccius, B. Untersuchungen über die Bedeuting der Distichie fur das Verstandnis der zerstreuten Blattstellung bei den Dikotylen. Bot. Archiv. Z. Gesamte Bot. 1940, 40, 58-150.

19. Hirmer, M. Zur Losung des Problems der Blattstellungen; Gustav Fisher: Jena, Germany, 1922; 105p.

20. Rees, A.R. The apical organization and phyllotaxis of the oil palm. Ann. Bot. 1964, 28, 57-69. [CrossRef]

21. Dumais, J.; Kwiatkowska, D. Analysis of surface growth in shoot apices. Plant J. 2002, 31, 229-241. [CrossRef] [PubMed]

22. Shipman, P.D.; Newell, A.C. Polygonal planforms and phyllotaxis on plants. J. Theor. Biol. 2005, 236, 154-197. [CrossRef]

23. Steeves, T.A.; Sussex, I.M. Patterns in Plant Development; Cambridge University Press: Cambridge, UK, 1989; 408p.

24. Smith, R.S.; Kuhlemeier, C.; Prusinkiewicz, P. Inhibition fields for phyllotactic pattern formation: A simulation study. Can. J. Bot. 2006, 84, 1635-1649. [CrossRef]

25. Smith, R.S.; Guyomarc'h, S.; Mandel, T.; Reinhardt, D.; Kuhlemeier, C.; Prusinkiewicz, P. A plausible model of phyllotaxis. Proc Natl. Acad. Sci. USA 2006, 103, 1301-1306. [CrossRef] [PubMed] 
26. Kwiatkowska, D.; Florek-Marwitz, J. Ontogenetic variation of phyllotaxis and apex geometry in vegetative shoots of Sedum maximum (L.) Hoffm. Acta Soc. Bot. Pol. 1999, 68, 85-95. [CrossRef]

27. Landrein, B.; Refahi, Y.; Besnard, F.; Hervieux, N.; Mirabet, V.; Boudaoud, A.; Vernoux, T.; Hamant, O. Meristem size contributes to the robustness of phyllotaxis in Arabidopsis. J. Exp. Bot. 2015, 66, 1317-1324. [CrossRef]

28. Barabé, D. Phyllotaxis: Open and closed systems. J. Biol. Syst. 1995, 3, 917-927. [CrossRef]

29. Bull-Hereñu, K.; Claßen-Bockhoff, R. Open and closed inflorescences: More than simple opposites. J. Exp. Bot. 2011, 62, 79-88. [CrossRef] [PubMed]

30. Zhang, T.; Cieslak, M.; Owens, A.; Wang, F.; Broholm, S.K.; Teeri, T.H.; Elomaa, P.; Prusinkiewicz, P. Phyllotactic patterning of gerbera flower heads. Proc. Natl. Acad. Sci. USA 2021, 118, e2016304118. [CrossRef] [PubMed]

31. Godin, C.; Golé, C.; Douady, S. Phyllotaxis as geometric canalyzation during plant development. Development 2020, 147 , dev165878. [CrossRef] [PubMed]

32. De Reuille, P.B.; Routier-Kierzkowska, A.-L.; Kierzkowski, D.; Bassel, G.W.; Schüpbach, T.; Tauriello, G.; Bajpai, N.; Strauss, S.; Alain Weber, A.; Kiss, A.; et al. MorphoGraphX: A platform for quantifying morphogenesis in 4D. eLife 2015, 4, e05864. [CrossRef] [PubMed]

33. Strauss, S.; Runions, A.; Lane, B.; Eschweiler, D.; Bajpai, N.; Trozzi, N.; Routier-Kierzkowska, A.-L.; Yoshida, S.; da Silveira, S.R.; Vijayan, A.; et al. MorphoGraphX 2.0: Providing context for biological image analysis with positional information. bioRxiv 2021. [CrossRef]

34. Bassel, G.W.; Smith, R.S. Quantifying morphogenesis in plants in 4D. Curr. Opin. Plant Biol. 2016, 29, 87-94. [CrossRef] [PubMed]

35. Green, P.B.; Linstead, P. A procedure for SEM of complex shoot structures applied to the inflorescence of snapdragon (Antirrhinum). Protoplasma 1990, 158, 33-38. [CrossRef]

36. Ovečka, M.; Sojka, J.; Tichá, M.; Komis, G.; Basheer, J.; Marchetti, C.; Šamajová, O.; Kubenová, L.; Šamaj, J. Imaging plant cells and organs with light-sheet and super-resolution microscopy. Plant Physiol. 2021, kiab349. [CrossRef] 